\title{
Extension du féminin - Les incertitudes de la langue, sous la direction de Marie-Jo Mathieu
}

\section{Rachele Raus}

\section{(2) OpenEdition}

1 Journals

\section{Édition électronique}

URL : https://journals.openedition.org/studifrancesi/39992

DOI : 10.4000/studifrancesi.39992

ISSN : 2427-5856

Éditeur

Rosenberg \& Sellier

\section{Édition imprimée}

Date de publication : 1 décembre 2004

Pagination : 430

ISSN : 0039-2944

\section{Référence électronique}

Rachele Raus, «Extension du féminin - Les incertitudes de la langue, sous la direction de Marie-Jo Mathieu », Studi Francesi [En ligne], 143 (XLVIII | II) | 2004, mis en ligne le 30 novembre 2015, consulté le 19 mai 2021. URL : http://journals.openedition.org/studifrancesi/39992 ; DOI : https://doi.org/ 10.4000/studifrancesi.39992

Ce document a été généré automatiquement le 19 mai 2021.

\section{(c)}

Studi Francesi è distribuita con Licenza Creative Commons Attribuzione - Non commerciale - Non opere derivate 4.0 Internazionale. 


\title{
Extension du féminin - Les incertitudes de la langue, sous la direction de Marie-Jo Mathieu
}

\author{
Rachele Raus
}

\section{RÉFÉRENCE}

Extension du féminin - Les incertitudes de la langue, sous la direction de Marie-Jo MATHIEU, Paris, Champion, 2002, pp. 142.

1 Ce livre est issu d'une table ronde, qui a suivi la publication en 1999 du rapport officiel sur les conditions linguistiques de la féminisation des noms de métiers. Dans l'Introduction (pp. 9-12), Marie-Jo MATHIEU pose ce texte comme une sorte d'état des lieux de la féminisation: il s'agit d'évaluer ses formes possibles, considérant les "incertitudes de la langue". Anne-Marie HOUDEBINE-GRAVAUD (Différenciations sexuelles dans les langues et identification sociale des femmes ou de la féminisation des noms de métiers, pp. 13-24) fait l'exemple des discriminations qui passent par le lexique et surtout par le "masculin générique", forme de neutralisation occultant la différence sexuelle. Pour l'A., il faut trouver des solutions de réécriture à partir des génériques réels. Edwige KHAZNADAR (Métalangage du genre: un flou artistique, pp. 25-44), se pose la question "d'où viennent les hésitations pour la dénomination de la femme" (p. 28), puisque le phénomène de l'alternance existe et est constant depuis le latin. Elle en conclut que la supériorité de l'homme fait ressentir la "dénomination masculine comme plus prestigieuse" (p. 28). Elle dénoncel'absence du neutre en langue française et le fait que le féminin soit conçu en France comme "cas marqué" du masculin. Pour que cela change, il faut une réflexion politico-culturelle, parce que "le masculin et le féminin sont la transposition linguistique de notre identité" (p. 41). Nicole CHOLEWKA (Féminin et familier, pp. 45-58) observe les usages réels de féminisation. Elle remarque des incertitudes de l'épicène ("mot qui garde une forme unique au masculin et au féminin", p. 49) qui soit est utilisé 
soit est substitué par une forme "surmarquée" (i.e. maire / mairesse). Pour ce qui est des suffixes esse-ette, teuse-trice, ils se lient partiellement à des connotations. Marina YAGUELLO (Le féminin comme catégorie biologique, sociale et grammaticale - Etude comparée du français et de l'anglais, pp. 59-67) analyse la différence entre la notion anglaise de gender et la française genre, la première ne conservant pas le sens étymologique de genus. De même, la paire male-female en anglais n'est pas lié e au domaine du sexe au contraire du couple français mâle-femelle. Cette attitude linguistique différente renvoie à une culture distincte. Martine COURTIER (Le féminin des noms de personne en - $(t)$ eur: résistances et concurrences, pp. 69-93) dépouille Le Monde (1998-2000) pour analyser les hésitations dans la féminisation des noms en - $(t)$ eur et dresser une typologie des usages par rapport aux contraintes sociolinguistiques, morphologiques, phonétiques. Elle revient sur les suffixes teuse-trice, -esse par rapport aux blocages liés à la connotation, en concluant que "plus les contraintes sont fortes, plus elles créent de concurrence" (p. 84). L'utilisation massive de l'épicène se veut un remède aux blocages et aux hésitations. Marie-Jo MAтHIEU (Le féminin n'est pas neutre, pp. 95-126) remarque que le mot féminisé est mis plus ou moins à distance par des mécanismes autonymiques (guillemets, parenthèses, commentaires). L'A. analyse aussi des compositions féminisées (ex. femme médecin), retraçant une échelle de gradation dans la mise à distance, jusqu'à un éventuel changement de registre de langue. L'A. passe à l'étude de la traduction de cinq romans policiers de la romancière américaine $\mathrm{P}$. Cornwell. Elle fait remarquer que "lorsque les traducteurs qui féminisent peu ou jamais certains termes...le font, c'est que le contexte est ironique, polémique ou familier" (p. 121). L'A. en conclut que le féminin est toujours mis à distance, parce qu'il n'est pas neutre. Dans la Conclusion générale (pp. 127-132), l'A. retrace les axes communs du texte: l'insécurité linguistique, renvoyant à une insécurité socio-culturelle; l'utilisation du féminin comme forme politiquement incorrecte; le problème du "neutre" qui en fait occulte la suprématie du masculin. 